\title{
Kani Karaca ve Bekir Sidkı Sezgin'in Ezan Tekbirleri Çerçevesinde Tony Adlı Ses Analiz Yazılımının İşlevselliği
}

\author{
Functionality of Sound Analysis Software Called Tony in the Framework of \\ Kani Karaca and Bekir Sidkı Sezgin's Adhan Takbirs
}

\author{
Muhammed Recai Çiftçi \\ Atıf (APA 6)/To cite this article \\ Makale Gönderim Tarihi/Received: 25/08/2019 \\ Makale Kabul Tarihi/Accepted: 23/09/2019 \\ Makale Yayın Tarihi/Published: 26/10/2019
}

Dr., email: muhammedrecai@gmail.com (DORCID ID: https://orcid.org/0000-0003-0915-982X

Ciftçi, M. R. (2019). Kani Karaca ve Bekir Sıdkı Sezgin'in ezan tekbirleri çerçevesinde Tony adlı ses analiz yazılımının işlevselliği. Atatürk Üniversitesi Güzel Sanatlar Enstitüsü Dergisi, 43, 248-255. doi: https://doi.org/10.32547/ataunigsed.610405

Research Article/Araştırma Makalesi

$\ddot{O} \mathbf{z}$

Genelde Türk Musikisi, özelde Türk Din Musiki sahasında yapılan akademik araștırmalarda bilgisayar destekli ses analiz yazılımlarının kullanımı son birkaç yıl içerisinde artış göstermiştir. Özellikle dini musikinin icra yönü ile ses sistemlerinin karșılaştırmalı olarak ele alındıkları bu araştırmalarda IVL, İcra Analizi, Makam ToolBox, Makam Box ve Tony gibi çeșitli ses analiz yazılımları kullanılmıștır. Bu çalışmada müzikoloji sahasında araştırmalarda bulunan öğrenci ve akademisyenlere kılavuzluk etmesi düşüncesiyle Kani Karaca ve Bekir Sıdkı Sezgin'in ezan tekbirleri çerçevesinde Tony adlı ses analiz yazılımının işlevselliği ortaya konulmaktadır. Ayrıca müzikal bir icranın frekans ve sent değerlerinin tespiti ve nazari sistemler ile karşılaştırmasının ne şekilde yapılacağı ele alınmaktadır. Araştırma sonucunda her iki icra arasında çok büyük oranda bir benzerlik bulunduğu, icralardaki aralık değerlerinin Arel-Ezgi-Uzdilek ses sisteminde belirtilen aralık değerleri ile büyük oranda örtüștügü ve ses analiz yazılımları ile Ezan formunun perde analizinin sağlıklı olarak yapılmasının mümkün olduğu anlaşılmıştır.

Anahtar Kelimeler: Ezan, Kani Karaca, Bekir S1dkı Sezgin, Ses Analiz Yazılımı

\begin{abstract}
The use of computer-aided audio analysis software has increased in the last few years in academic researches in the field of Turkish Music in general and Turkish Religion Music in particular. Especially, in these researches where the performance of religious music and the sound systems are compared, various sound analysis software such as IVL, Performance Analysis, Maqam ToolBox, Maqam Box and Tony have been used. In this study, the functionality of the sound analysis software named Tony is introduced in the framework of Kani Karaca and Bekir Sidkı Sezgin's Adhan Takbirs in order to guide students and academicians in the field of musicology. Besides, determination of frequency and cent values of a musical performance and how it will be compared with theoretical systems are discussed. As a result of the research, it is understood that there is a great similarity between the two performances, the interval values in the performances overlap with the interval values specified in the Arel-Ezgi-Uzdilek sound system and it is possible to perform the pitch analysis of the Adhan form soundly with sound analysis software.
\end{abstract}

Keywords: Adhan, Kani Karaca, Bekir Sidkı Sezgin, Sound Analysis Software

\section{Giriş}

21. yy'ın baş döndürücü bir şekilde ilerleyen teknolojisi ile birlikte üretilen IVL (Akkoç, 2002, s. 285-293), İcra Analizi (Karaosmanoğlu, 2003), Makam ToolBox (Bozkurt, 2008, s. 1-13), Makam Box (Atıc1, 2016) ve Tony gibi ses analiz yazılımları daha önce Türk Müziği üzerine yapılan araştırmalarda kullanılmıştır. Bunlardan Makam Box ve Tony'nin Türk Din Musikisi sahasındaki araştırmalarda kullanımında da bir artış gözlenmektedir. Bu türden araştırmaların kongre ve sempozyum gibi akademik organizasyonlar vesilesiyle bilim insanları tarafindan takdirle karşılandığı görülmekte ve bu çalışmaların alana farklı bakış açıları kazandırdığı düşünülmektedir.

Daha önceki araştırmalarda (Çiftçi, 2019, s. 35) kullanılan Tony adlı ses analiz yazılımının kullanımı ile alakalı, akademisyenlerden gelen talepler doğrultusunda böyle bir çalışma yapmak gerekliliği hasıl olmuştur.

Bu araştırmada, Türk müziği tarihinde her ikisi de sahada yetkin çok önemli birer icracı olarak görülen ve hayata veda ettikten sonra da bu sahada şöhretlerini sürdüren Kani Karaca ve Bekir Sıdkı Sezgin'in ezan tekbirleri ele alınmaktadır. Zira her iki sanatkâr da yetiştirdikleri icracılarla bugün Türk Müziği sahasında tavır ve üslup olarak yaşamakta ve icra kayıtlarını dinleyerek kendilerini örnek almaya çalışanlara da rehberlik etmeyi sürdürmektedir.

Özellikle müzikoloji çalışmalarında kullanılan ses analiz programlarının işlevselliğine ve akademisyenler tarafindan ne şekilde kullanılacağına dair MakamBox haricinde Türkçe bir kılavuza basit bir literatür taraması ile rastlanılmamaktadır. Tony programı ile alakalı olarak programı dizayn eden akademisyenler tarafindan programın temel fonksiyonlarının ele alındığı İngilizce bir çalışma (Mauch, Cannam, Bittner, Fazekas, Salamon, Dai, Bello, \& Dixon, 2015) bulunmaktadır. Bununla birlikte ezan formunda kullanılan ses aralıklarının da nazarî sistemlerle örtüşürlüğüne dair herhangi bir akademik çalışma bulunmamaktadır. Ayrıca araştırma konusu olan müzikal 
niteliğe sahip bir icranın nasıl bir yöntemle analiz edileceği konusu da lisans eğitimi düzeyinden itibaren her seviyedeki akademisyenler ile müzikologların ihtiyaç duyabileceği bir konu olarak karşımızda durmaktadır.

$\mathrm{Bu}$ noktadan hareketle araştırmanın problem cümlesi "Ses analiz yazılımlarının Türk Din Musikisi alanında kullanılabilirliği mümkün müdür?” şeklinde oluşturulmuştur. Bu ana problem çerçevesinde cevap aranacak araştırma soruları ise aşağıdaki gibidir.

1. Kani Karaca ve Bekir Sıdkı Sezgin'in ezan tekbirlerindeki ses aralıklarının ses analiz yazılımı kullanılarak karşılaştırılmasıyla ne düzeyde bir benzerlik ortaya çıkmaktadır?

2. Kani Karaca ve Bekir Sıdkı Sezgin'in ezan tekbirlerindeki perde aralık değerlerinin Arel-Ezgi-Uzdilek ses sisteminde belirtilen aralık değerleri ile örtüşürlüğü ne düzeydedir?

\section{Yöntem}

Betimsel bir niteliğe sahip olan bu araştırmada doküman analizi yöntemi uygulanmıştır. Araştırmada öncelikle eldeki ses kayıtları, Tony adlı ses analiz yazılımı ile analiz edilmiş ve elde edilen aralık değerleri karşılaştırılmıştır. Söz konusu aralık değerlerinin Arel-Ezgi-Uzdilek sistemi ile olan örtüşürlüğü de ölçüldükten sonra araştırmanın problem cümlesinin ne derecede doğrulanabilir olduğu ortaya konulmuştur. Gerçekleştirilen bütün bu aşamalar da çalışma içerisinde detaylandırılarak, Tony adlı ses analiz programının işlevselliği ve perde analizi konusunda basit bir kılavuz oluşturulmuştur.

Araştırmada veriler Kani Karaca ve Bekir Sıdkı Sezgin'in Hicaz makamında okudukları ezanların ilk 2 tekbirinden elde edilmiştir. Söz konusu okuyuşlara Youtube adlı internet sitesinden ulaşılmıştır.

Her iki icranın da Tony adlı ses analiz yazılımı ile frekans değerleri tespit edilmiş, bu değerler Microsoft Excel programı yardımıyla logaritmik formüller kullanılarak sent değerlerine dönüştürülmüştür. Bu şekilde her iki icranın da karşılaştırılması mümkün hale gelmiştir. Bu araştırmada sadece ikili aralıklar karşılaştırılmıştır. Bu araştırma ile ilgili farklı verilerin ortaya çıkmasıyla daha farklı sonuçlara ulaşılması mümkündür.

Çalışmanın evreninin genişliğinden kaynaklanan sorunların önüne geçmek için örneklem yöntemi kullanılmıştır (Karahasanoğlu ve Yavuz, 2015, s. 10). Araştırmanın evrenini, Kani Karaca ve Bekir Sıdkı Sezgin'in ezan icraları ile çok çeşitli özelliklere sahip ses analiz yazılımları oluşturmaktadır. Örneklemini ise her iki okuyucunun Hicaz makamında okudukları ezan ile Tony adlı ses analiz yazılımı teşkil etmektedir.

Araştırmada ele alınan ezan icraları, Finale adlı nota yazım programı ile notalandırılmıştır. İcra içerisinde tespit edilen en küçük hece bir birim olarak kabul edilmiş, bu hece bir "sekizlik" nota olarak tespit edilmiştir.

Bu araştırmada kullanılan ve çok satırlı yazım tekniği adı verilen notasyon modelinde (Yeprem, 2017, s. 408), ilk satırda Sol anahtarlı, ikinci satırda Fa anahtarlı $(\mathrm{La}=440 \mathrm{~Hz})$, üçüncü satırda ise derece sistemine dayanan numerik notasyon bulunmaktadır. Dördüncü satıra da, icranın tespit edilebilen sent değerlerine dayalı bir seyir grafiği yerleştirilmiştir.

Sol ve Fa anahtarlı satır ile numerik notasyonda makamın donanımı yerleştirilmemiş, arızalar icra içerisinde gösterilmiştir. Numerik notasyonda makamın karar sesi "1" rakamı ile gösterilmiş, karardan daha pest tarafa yönelen notayı ifade eden rakamın altına bir çizgi ilave edilmiştir. Her üç satırdaki notasyon, dördüncü satırdaki sent değerinin bulunduğu noktaya göre dikey olarak hizalanarak konumlandırılmıştır.

Aralık değerlerinin ses sistemleri ile örtüşürlüğü konusunda makamın karakterini belirleyen en küçük unsur olarak 1 komalık bir tolerans payı (22.64 sent) belirlenmiş, bu değerin üzerinde pest veya tiz tınlayan aralıkların sistemle örtüşmediği ifade edilmiştir. İlgili tabloda bu aralıklar zemini koyulaştırarak gösterilmiştir.

\section{Bulgular ve yorum}

\subsection{Tony ses analiz yazılımı}

TONY, ücretsiz olarak hizmete sunulan bir ses analiz yazılımıdır. Bu yazılımda, monofonik seste temel frekans (F0) tahmini için pYIN adlı bir algoritma kullanılmaktadır. pYIN, popüler bir algoritma olan, Makam ToolBox ve MakamBox programları tarafindan da kullanılan "YIN" algoritmasının bir modifikasyonudur (Mauch ve Dixon, 2014). 


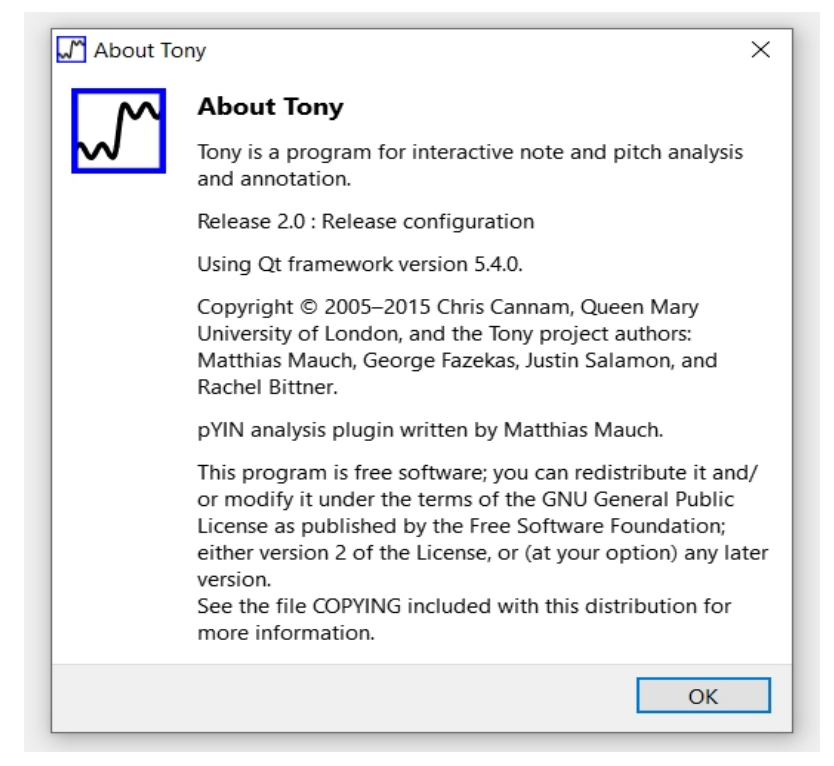

Resim 1. Tony ses analiz yazılımı hakkında

TONY programı bir ses dosyası ile çalıştırıldığında aşağıdaki şekilde bir arayüz görülmektedir. ${ }^{1}$

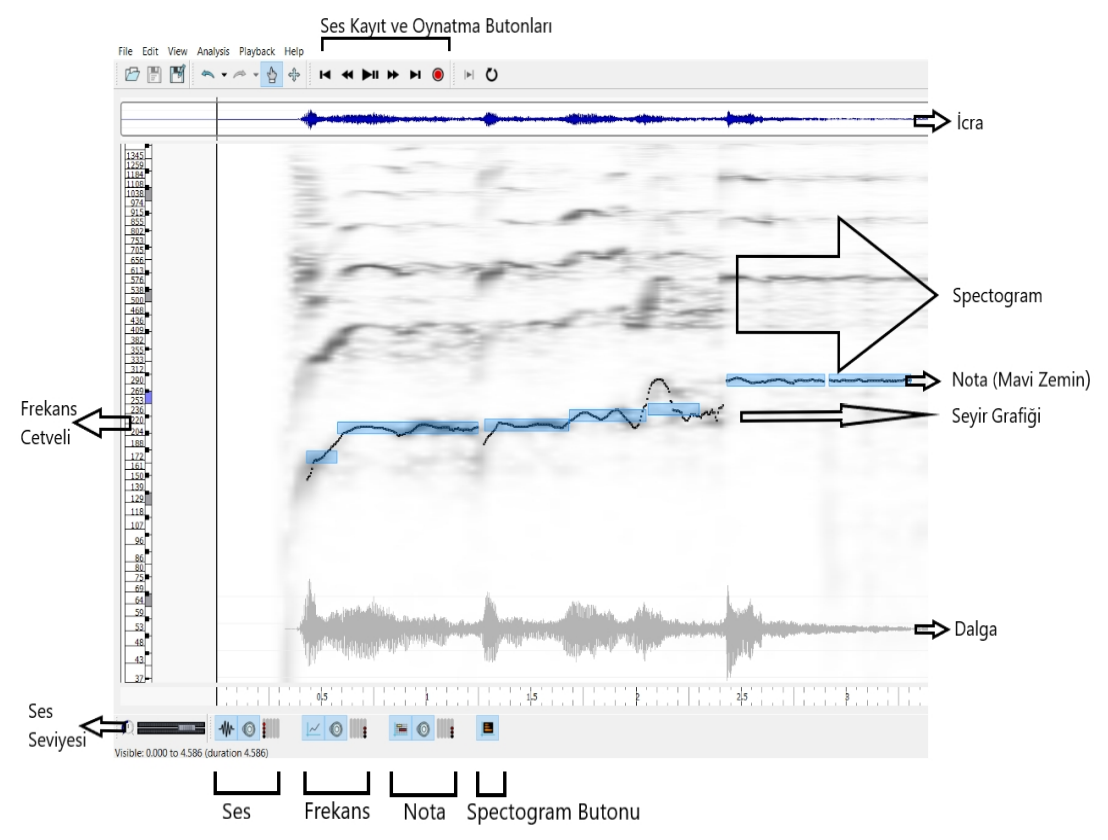

Resim 2. Tony programının arayüzü

Analiz edilmek istenen icra, programı çalıştırdıktan sonra üzerine sürüklemek ya da FILE menüsünden dosya konumunu bularak açmak suretiyle program üzerinde incelemeye hazır hale gelmektedir.

İcranın frekans değerleri, FILE menüsündeki EXPORT PITCH TRACK DATA komutuyla, Microsoft Office yazılım paketinin içeriğinde bulunan EXCEL program dosyası formatında alınabilmektedir.

TONY'den EXPORT edilen frekans değerleri ile ilgili EXCEL dosyası açıldığında iki sütun halinde (A/B) zaman bilgisi ve frekans değerleri -Saniye/Hertz birimlerinde- görüntülenmektedir. İcranın henüz başlamadığı zaman karşıllı̆ındaki Hertz sütununda "0" değerleri görülmektedir. Bu program her 1 saniyelik süre için -173 ya da 174adet ayrı frekans değeri tespit edebilmektedir.

${ }^{1}$ Benzer bir versiyonu (Mauch, 2015) bulunan bu resim (bkz. Resim 2), programın 5.4.0. numaralı sürümünde araştırmacı tarafindan kullanılan ses dosyaları ile açılmış halinden elde edilmiş ve mümkün olduğunca Türkçe kavramlarla notlandırılmıştır. 


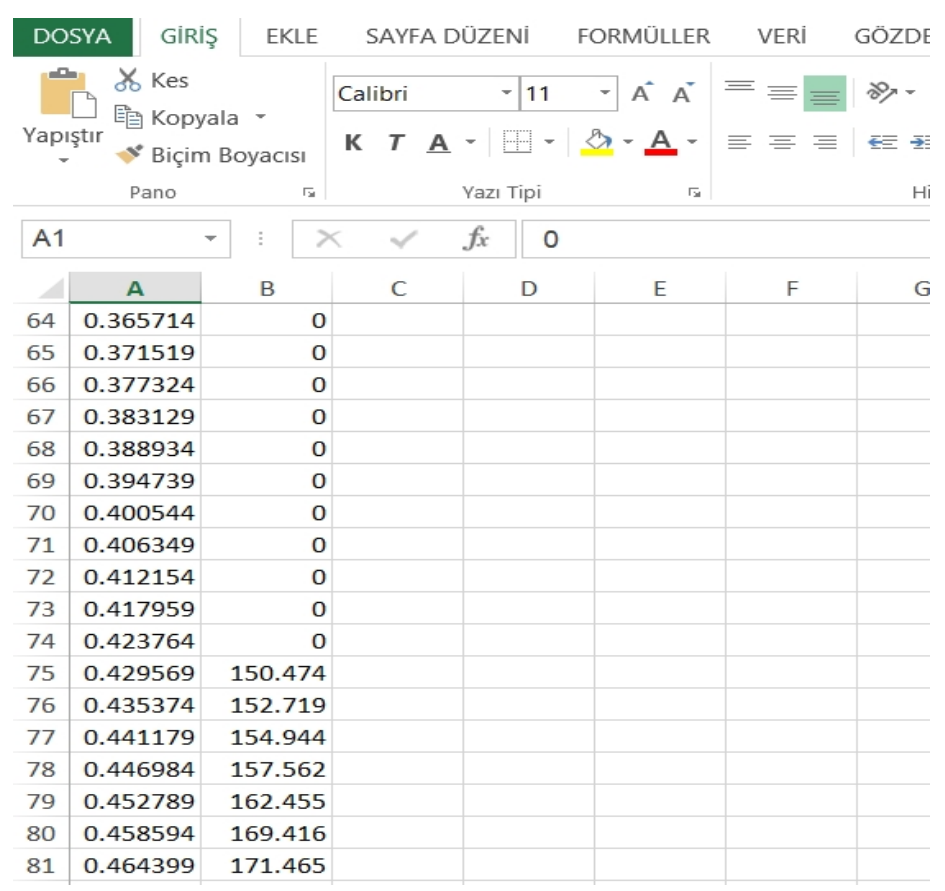

Resim 3. Bir icranın zaman (A) ve frekans değerleri (B)

Frekans değerlerinin oktavı işitsel olarak eşit 1200 aralı̆̆a bölen birim olan sent değerine (Karaosmanoğlu, 2017, s. 79) çevrilmesini sağlamak için tabloda görülen logaritmik formüllerin frekans sütununun en başına işlenmesi gerekmektedir. Bu şekilde $\mathrm{C}$ sütununda görülen sent değerleri elde edilmektedir. Bu sent değerleri, TONY'nin Hertz cinsinden frekanslarını ölçtüğü seslerin, MIDI standardına göre eksi birinci oktavdaki Do'nun frekansı olan 8.1757989 Hertz'lik ses (B1 hücresi) ile oluşturdukları müzikal aralıklardır.

\begin{tabular}{|c|c|c|c|c|c|}
\hline B1 & 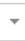 & $x$ & $f_{x}$ & \multicolumn{2}{|c|}{$=13.75 / 2^{\wedge}(9 / 12)$} \\
\hline 2 & \multicolumn{2}{|r|}{ A } & \multicolumn{2}{|c|}{ B } & C \\
\hline 1 & & & \multicolumn{2}{|c|}{8.1757989} & \\
\hline 970 & \multicolumn{2}{|r|}{5.613424036} & \multicolumn{2}{|c|}{87.764} & 4,109 \\
\hline 1022 & \multicolumn{2}{|r|}{5.915283446} & \multicolumn{2}{|c|}{114.452} & 4,569 \\
\hline 1074 & \multicolumn{2}{|r|}{6.217142857} & \multicolumn{2}{|c|}{110.928} & 4,515 \\
\hline 1104 & \multicolumn{2}{|r|}{6.391292517} & \multicolumn{2}{|c|}{114.098} & 4,563 \\
\hline 1189 & \multicolumn{2}{|r|}{6.884716553} & \multicolumn{2}{|c|}{113.454} & 4,554 \\
\hline
\end{tabular}

Resim 4. Sent değer tespiti için formül kullanımı

\begin{tabular}{|c|c|c|c|c|c|}
\hline C970 & $v$ & $x \quad \checkmark$ & $=12$ & $0^{*} \operatorname{LOG}$ & $B \$ 1,2)$ \\
\hline 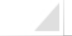 & \multicolumn{2}{|r|}{ A } & B & C & D \\
\hline 1 & & & 8.1757989 & & $\mathbf{T}$ \\
\hline 970 & \multicolumn{2}{|r|}{5.613424036} & 87.764 & 4,109 & \\
\hline 1022 & \multicolumn{2}{|r|}{5.915283446} & 114.452 & 4,569 & \\
\hline 1074 & \multicolumn{2}{|r|}{6.217142857} & 110.928 & 4,515 & \\
\hline 1104 & \multicolumn{2}{|r|}{6.391292517} & 114.098 & 4,563 & \\
\hline 1189 & \multicolumn{2}{|r|}{6.884716553} & 113.454 & 4,554 & \\
\hline
\end{tabular}

Resim 5. Bir icranın zaman (A), frekans (B) ve sent değerleri (C)

İcraya ait sent değerleri elde edildikten sonra, sıradaki aşama icradaki lafız ve perdelerin hangi sent değerine karşılık geldiğinin tespit edilmesidir. Bu aşama için milisaniyelik oynatma modu olan bir ses oynatma yazılımına gerek duyulmaktadır. Eldeki icra, tercih edilecek bir yazılım ile milisaniyelik modda oynatılıp bir perdenin en belirgin tınlama noktası işaretlenerek, EXCEL dosyasındaki ilgili Saniye/Frekans/Sent Değeri satırına ait olduğu "lafiz" ile birlikte not edilmektedir. 


\begin{tabular}{|c|c|c|c|c|c|}
\hline F27 & $\checkmark$ & $\times \quad \checkmark$ & $f_{x}$ & & \\
\hline$\Delta$ & A & B & C & D & E \\
\hline 5 & SANIYE & HERTZ & SENT & LAFIZ & PERDE \\
\hline 6 & 0.5746939 & 196.094 & 5,501 & $A L$ & SOL \\
\hline 7 & 0.7198186 & 216.912 & 5,676 & LA & LA \\
\hline 8 & 0.9810431 & 219.429 & 5,696 & HÜ & LA \\
\hline 9 & 1.0913379 & 215.926 & 5,668 & EK & LA \\
\hline 10 & 1.3641723 & 220.965 & 5,708 & BER & LA \\
\hline 11 & 1.526712 & 220.576 & 5,705 & $A L$ & LA \\
\hline 12 & 1.7240816 & 235.1 & 5,815 & LA & si \\
\hline 13 & 2.060771 & 281.088 & 6,124 & HÜ & DO \\
\hline 14 & 2.1536508 & 275.543 & 6,090 & EK & DO \\
\hline 15 & 2.7109297 & 294.688 & 6,206 & BER & RE \\
\hline
\end{tabular}

Resim 6. Sent değerine karşılık gelen lafiz ve perdenin işlenmesi

Bu aşamadan sonra, elde edilen veriler ışı̆̆ında icraların Arel-Ezgi-Uzdilek ses sistemi ile olan örtüşürlüğ̈̈ ortaya konulmuştur.

\subsection{Kani Karaca'nın Ezan Tekbirleri}

\subsubsection{Notasyon}

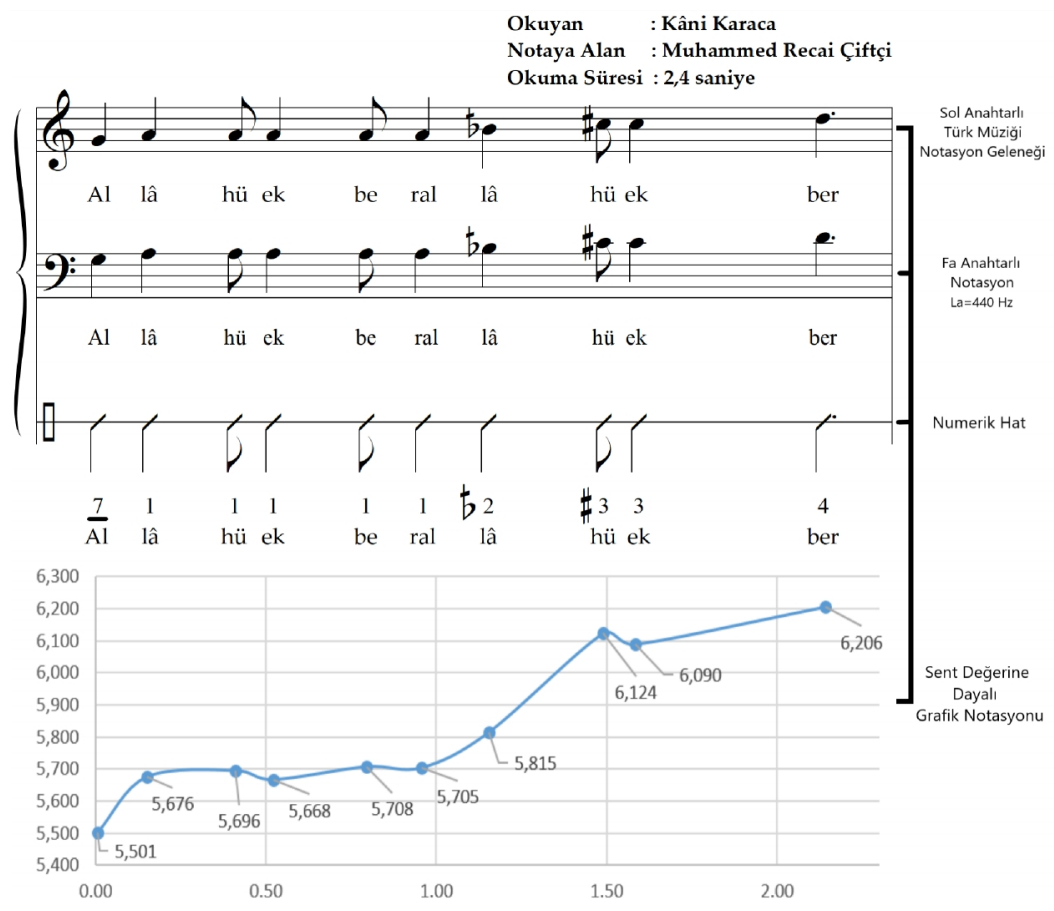

Resim 7. Kani Karaca'nın ezan tekbirleri notasyonu

\subsubsection{Perde ve aralık değerleri}

Rast perdesinden icraya başlayan Kani Karaca, hemen Hicaz makamının karar sesi olan Dügâh perdesine geçmiştir. Kısa bir süre bu perdeyi pekiştirdikten sonra Hicaz çeşnisinin seslerini ardışı şekilde kullanarak makamın güçlüsü olan Neva perdesine ulaşan okuyucu, burada yarım karar göstermiştir.

İcranın perde ve sent değerlerine ait tablo şu şekildedir.

Tablo 1

Kani Karaca icrasının sent değerleri

\begin{tabular}{ccccccccccc}
\hline LAFIZ & AL & LA & HÜ & EK & BER & AL & LA & HÜ & EK & BER \\
\hline PERDE & SOL & LA & LA & LA & LA & LA & SI & DO & DO & RE \\
\hline SENT & 5.501 & 5.676 & 5.696 & 5.668 & 5.708 & 5.705 & 5.815 & 6.124 & 6.090 & 6.206 \\
\hline
\end{tabular}

İcrada kullanılan aralıklara bakıldığında Rast-Dügah aralığının 1.5 komaya yakın dar, Dik Kürdi-Nim Hicaz aralığının ise 1.5 koma kadar geniş olduğu görülmektedir. Bu icranın kısmen AEU ses sistemi ile örtüştüğü söylenebilir. İcranın sent cinsinden aralık değerleri ile ilgili tablo şu şekildedir. 
Tablo 2

İcra ve AEU sistemi karşılaştırması

\begin{tabular}{cccc}
\hline ARALIK & AEU & ICRA & FARK \\
\hline SOL-LA & 204 & 175 & 29 \\
\hline LA-LA & $*$ & 20 & $*$ \\
\hline LA-LA & $*$ & 28 & $*$ \\
\hline LA-LA & $*$ & 40 & 3 \\
\hline LA-LA & $*$ & 110 & 3 \\
\hline LA-SI & 113 & 309 & 37 \\
\hline Sİ-DO & 272 & 34 & $*$ \\
\hline DO-DO & $*$ & 116 & 3 \\
\hline DO-RE & 113 & & $*$ \\
\hline
\end{tabular}

\subsection{Bekir Sıdkı Sezgin'in Ezan Tekbirleri}

\subsubsection{Notasyon}

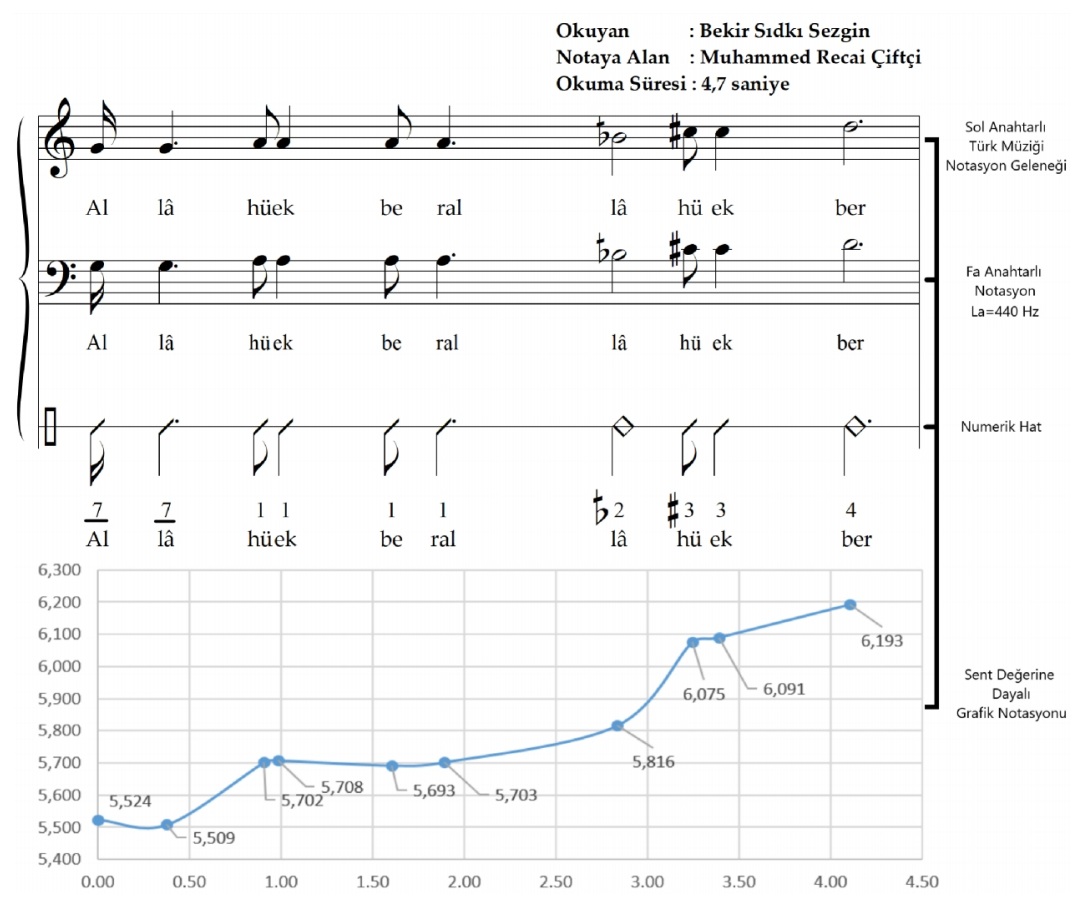

Resim 8. Bekir S1dkı Sezgin'in ezan tekbirleri notasyonu

\subsubsection{Perde ve aralık değerleri}

Rast perdesinden icraya başlayan Bekir Sıdkı Sezgin, üçüncü hece ile birlikte Hicaz makamının karar sesi olan Dügah perdesine geçmiştir. Çok kısa bir süre bu perdeyi vurguladıktan sonra Hicaz çeşnisinin seslerini ardışık şekilde kullanarak makamın güçlüsü olan Neva perdesine ulaşan okuyucu, burada yarım karar göstermiştir.

İcranın perde ve sent değerlerine ait tablo şu şekildedir.

Tablo 3

Bekir Sıdkı Sezgin icrasının sent değerleri

\begin{tabular}{ccccccccccc}
\hline LAFIZ & AL & LA & HÜ & EK & BER & AL & LA & HÜ & EK & BER \\
\hline PERDE & SOL & SOL & LA & LA & LA & LA & SI & DO & DO & RE \\
\hline SENT & 5.524 & 5.509 & 5.702 & 5.708 & 5.693 & 5.703 & 5.816 & 6.075 & 6.091 & 6.193 \\
\hline
\end{tabular}

İcrada kullanılan aralıklara bakıldığında çoğunun yarım koma civarında dar yapıda olduğu görülmektedir. Bu icranın tamamen AEU ses sistemi ile örtüştüğü söylenebilir. İcranın sent cinsinden aralık değerleri ile ilgili tablo şu şekildedir. 
Tablo 4

İcra ve AEU sistemi karşılaştırması

\begin{tabular}{cccc}
\hline ARALIK & AEU & ICRA & FARK \\
\hline SOL-SOL & $*$ & 15 & 11 \\
\hline SOL-LA & 204 & 193 & $*$ \\
\hline LA-LA & $*$ & 6 & 15 \\
\hline LA-LA & $*$ & 10 & $*$ \\
\hline LA-LA & $*$ & 113 & 0 \\
\hline LA-SI & 113 & 259 & 13 \\
\hline Sİ-DO & 272 & 16 & $*$ \\
\hline DO-DO & $*$ & 102 & 11 \\
\hline DO-RE & 113 & & \\
\hline
\end{tabular}

\subsection{Karşılaştırma ve değerlendirmeler}

Kani Karaca ve Bekir Sıdkı Sezgin, Hicaz makamında okudukları ezanlara Hicaz makamının yedeni olarak tarif edilen Rast perdesi ile başlamaktadır. Her ikisi de Rast perdesinden sonra hemen Dügah perdesine uzanarak Hicaz çeşnisinin seslerini ardışık şekilde kullanmış ve makamın güçlü perdesi olan Neva perdesinde yarım karar göstermiştir. Bu çerçevede her iki okuyuş arasında tamamen bir benzerlik bulunduğu ifade edilebilir.

Okuyucuların Rast-Neva aralığındaki ses bölgesini kullandıkları görülmüştür. Bu açıdan tamamen bir benzerlik bulunmaktadır.

Her iki okuyuşta da Rast-Dügah, Dügah-Dik Kürdi, Dik Kürdi-Nim Hicaz, Nim Hicaz-Neva aralıkları birer defa kullanılmıştır. Bu çerçevede tamamen bir benzerlik bulunmaktadır.

Frekans ölçümü ile her iki okuyucunun da okuyuşta aynı akordu kullandıkları görüldüğünden, akort kullanımında da tamamen bir benzerliğin bulunduğu söylenebilir.

Okuyuş süreleri ele alındığında Kani Karaca'nın, Bekir Sıdkı Sezgin'in toplam okuyuş süresinin yarısı kadar bir sürede icrada bulunduğu anlaşılmaktadır. Buradan hareketle ezan okuyuşuna Karaca'nın, Sezgin'e göre daha süratli bir başlangıç yaptığı söylenebilir. Bu noktada tamamen bir farklılık bulunmaktadır.

\section{Sonuç}

Kani Karaca ve Bekir Sıdkı Sezgin'in okudukları Hicaz makamındaki ezanların ilk tekbirleri örneğinde Tony adlı ses analiz yazılımının işlevselliği bu araştırma sürecinde ortaya konulmuştur. Araştırma sürecinde elde edilen verilerin analiz edilmesiyle şu sonuçlar ortaya çıkmıştır.

1. alt probleme ilişkin değerlendirme ve sonuç: Araştırmada ortaya koyulan verilerle, Kani Karaca ve Bekir Sıdkı Sezgin'in ezan tekbirlerindeki ses aralıklarının ses analiz yazılımı kullanılarak karşılaştırılmasının mümkün olduğu görülmüştür. Yapılan karşılaştırmalar sonucunda her iki icra arasında çok büyük oranda bir benzerlik bulunduğu anlaşılmaktadır.

2. alt probleme ilişkin değerlendirme ve sonuç: Kani Karaca’nın icrasındaki Rast-Dügah aralığının 1.5 komaya yakın dar ve Dik Kürdi-Nim Hicaz aralığının 1.5 koma kadar geniş olduğu görülmüş ve bu aralıklarda icrasal bir farklılık olduğu anlaşılmıştır. Bununla birlikte Karaca ve Sezgin'in ezan tekbirlerindeki perde aralık değerlerinin Arel-Ezgi-Uzdilek ses sisteminde belirtilen aralık değerleri ile büyük oranda örtüştüğü görülmektedir.

Türk Din Musikisi alanında, bilimsel nitelikte çalışmaların ortaya konulmasına devam edilebilmesi için bilim ve teknolojinin insanlığa sunduğu araç ve gereçlerin, araştırma süreçlerine daha çok dahil edilmesi gerekmektedir.

Ezan ile alakalı karşılaştırmalı çalışmalara da bu alanda yer vermenin önemli olduğu aşikardır. Ayrıca günde 5 vakit olarak minarelerden namaza çağrı amacıyla okunan ezanın 21. yy. insanının devamlı değişim gösteren psikolojisine ve hâlet-i rûhiyesine müspet yönde tesiri için, makamların her vakitte insan sağlığına ve psikolojisine ne gibi etkileri olduğu yönündeki multidisipliner araştırmalara ihtiyaç duyulduğunu ifade etmek gerekmektedir.

\section{Kaynakça}

Akkoç, C. (2002). Non-deterministic scales used in traditional Turkish music. Journal of New Music Research, 31(4), 285-293.

Atıcı, B. M. (2016). Makam müzikleri için etkileşimli eğitim sistemi (Yüksek lisans tezi). Bahçeşehir Üniversitesi Fen Bilimleri Enstitüsü Ses Teknolojileri Bilim Dalı, İstanbul. YÖK tez veri tabanından erişildi (Tez No. 449245). 
Bozkurt, B. (2008). An automatic pitch analysis method for Turkish maqam music. Journal of New Music Research, 37(1), 1-13. doi: 10.1080/09298210802259520

Çiftçi, M. R. (2019). İstanbul'daki Hristiyan ve Müslüman mabedlerinde okunan Tevrat, Zebur, Incil ve Kuran-ı Kerim ayetlerinin karşılaştırmalı müzikal analizi (Doktora tezi). Marmara Üniversitesi Sosyal Bilimler Enstitüsü İslâm Tarihi ve Sanatları Ana Bilim Dalı, İstanbul. YÖK tez veri tabanından erişildi (Tez No. 548029).

Karahasanoğlu, S., \& Yavuz, E. D. (2015). Müzikte araştırma yöntemleri. İstanbul: İTÜ Türk Musikisi Devlet Konservatuarı Yayınları.

Karaosmanoğlu, M. K. (2003). İcra örnekleri üzerinde ölçümler, değişik ses sistemleriyle icralar ve değerlendirme [Sunu]. Türk makam müziği perdelerini çalabilen piyano imâli projesi. Erişim adresi: https://www. academia.edu/30925402/\%C4\%B0cra_\%C3\%96rnekleri_\%C3\%9Czerinde_\%C3\%961\%C3\%A7\%C3\%B Cmler_De \%C4\%9Fi\%C5\%9Fik_Ses_Sistemleriyle_\%C4\%B0cralar_ve_De $\%$ C4\% $\%$ Ferlendirme

Karaosmanoğlu, M. K. (2017). Müzik aritmetiği ve ses sistemleri. İstanbul: İTÜ Vakfı Yayınları.

Mauch, M., \& Dixon, S. (2014, May). PYIN: A fundamental frequency estimator using probabilistic threshold distributions, in Proceedings of the IEEE International Conference on Acoustics, Speech and Signal Processing (ICASSP 2014), Florence, Italy. Erişim adresi: https://www.eecs.qmul.ac.uk/ simond/pub/ 2014/MauchDixon-PYIN-ICASSP2014.pdf

Mauch, M., Cannam, C., Bittner, R., Fazekas, G., Salamon, J., Dai, J., Bello, J., \& Dixon, S. (2015, May). Computer-aided melody note transcription using the Tony software: accuracy and efficiency, in Proceedings of the First International Conference on Technologies for Music Notation and Representation, Sorbonne University, Paris. Erişim adresi: http://tenor2015.tenor-conference.org/program.html

Yeprem, M. S. (2017). İlahiyat fakültelerinde müzikal işitme, okuma ve yazma çalışmaları. Ş. Özdemir ve A. Gün (Ed.), Geçmişten Günümüze Uluslararası Dini Musiki Sempozyumu Bildiriler Kitabı (s. 399-409) içinde. Amasya. Erişim adresi: https://ilahiyat.amasya.edu.tr/media/1427/musiki-baski.pdf 